\title{
What Does Social Justice Require For The Public's Health? Public Health Ethics And Policy Imperatives
}

Lawrence O. Gostin

Georgetown University Law Center, gostin@law.georgetown.edu

Madison Powers

Kennedy Institute of Ethics, powersm@georgetown.edu

Georgetown Public Law and Legal Theory Research Paper No. 920480

This paper can be downloaded free of charge from:

https://scholarship.law.georgetown.edu/facpub/483

http://ssrn.com/abstract $=920480$

25 Health Aff. 1053-1060 (2006)

This open-access article is brought to you by the Georgetown Law Library. Posted with permission of the author. Follow this and additional works at: https://scholarship.law.georgetown.edu/facpub

Part of the Health Law and Policy Commons 


\section{What Does Social Justice Require For The Public's Health? Public Health Ethics And Policy Imperatives}

Social justice demands more than fair distribution of resources in extreme public health emergencies.

\section{by Lawrence 0 . Gostin and Madison Powers}

ABSTRACT: Justice is so central to the mission of public health that it has been described as the field's core value. This account of justice stresses the fair disbursement of common advantages and the sharing of common burdens. It captures the twin moral impulses that animate public health: to advance human well-being by improving health and to do so particularly by focusing on the needs of the most disadvantaged. This Commentary explores how social justice sheds light on major ongoing controversies in the field, and it provides examples of the kinds of policies that public health agencies, guided by a robust conception of justice, would adopt. [Health Affairs 25, no. 4 (2006): 1053-1060; 10.1377/hlthaff .25.4.1053]

T USTICE IS VIEWED AS SO CENTRAL TO THE MISSION of public health that it has been described as the field's core value: "The historic dream of public health...is a dream of social justice." This Commentary addresses a single question of extraordinary social and political importance: What does social justice require for the public's health? Our thesis is that justice can be an important organizing principle for public health.

Justice alone cannot determine the "correct" policy or supply an answer to every question regarding the broad direction for public health; neither can any other single organizing principle. However, there are certain core commitments that all who embrace even a modest conception of social justice recognize as important, and those commitments can shed light on the major ongoing controversies in the field: the legitimate scope of public health, the balance between public health and

Larry Gostin (gostin@law.georgetown.edu) is associate dean and a professor at the Georgetown University Law Center in Washington, D.C.; director of the university's Center for Law and the Public's Health; and a professor at the Johns Hopkins Bloomberg School of Public Health in Baltimore, Maryland. Madison Powers is director and senior research scholar at the Kennedy Institute of Ethics, Georgetown University, and an associate professor in its Department of Philosophy. 
civil liberties, and the appropriate roles of the federal government and the states. More importantly, this paper shows how public health based on social justice gives rise to important policy imperatives such as improving the public health system, reducing socioeconomic disparities, addressing health determinants, and planning for health emergencies with an eye on the needs of the most vulnerable. Before examining the major controversies and making policy recommendations, we provide our particular account of justice in public health.

\section{What Is 'Justice,' And How Important Is It In Public Health?}

Among the most basic and commonly understood meanings of justice is fairness or reasonableness, especially in the way people are treated or decisions are made. ${ }^{2}$ Our account of justice stresses the fair disbursement of common advantages and the sharing of common burdens. It captures the twin moral impulses that animate public health: to advance human well-being by improving health and to do so by focusing on the needs of the most disadvantaged. An integral part of bringing good health to all is the task of identifying and ameliorating patterns of systematic disadvantage that undermine the well-being of people whose prospects for good health are so limited that their life choices are not even remotely like those of others. ${ }^{3}$ These two aspects of justice- - health improvement for the population and fair treatment of the disadvantaged - create a richer understanding of public health.

A core insight of social justice is that there are multiple causal pathways to numerous dimensions of disadvantage. These include poverty, substandard housing, poor education, unhygienic and polluted environments, and social disintegration. These and many other causal agents lead to systematic disadvantage not only in health, but also in nearly every aspect of social, economic, and political life. Inequalities beget other inequalities, and existing inequalities compound, sustain, and reproduce a multitude of deprivations. ${ }^{4}$

Our account of social justice is interventionist, not passive or market-driven, vigorously addressing the determinants of health throughout the lifespan. It recognizes that there are multiple causes of ill and good health, that policies and practices affecting health also affect other valued dimensions of life, and that health is intimately connected to many of the important goods in life. Empirical inquiries, therefore, are critical to justice in public health. Data can help determine who are most vulnerable and at greatest risk, how best to reduce the risk or ameliorate the harm, and how to fairly distribute services and benefits.

\section{The Justice Perspective In Public Health}

The field of public health is in the midst of a crisis of public confidence. American culture openly tolerates the expression and enjoyment of wealth and privilege and is inclined to view health as a matter of personal responsibility. Meanwhile, the public has become skeptical of government's ability to ameliorate the harshest consequences of socioeconomic disparities. At its deepest level, some believe that 
government's purpose should not be to redress economic and social disadvantage, and this may be doubly so for administrative agencies dedicated to public health and the pursuit of science. We believe that it is time to rethink this view, and the justice perspective offers an alternative. Values of socioeconomic fairness are just as important to health as the prevailing values of personal license and free enterprise. The justice perspective offers a different way of seeing problems that have long plagued the field of public health.

Legitimate scope of the public health enterprise. Perhaps the deepest, most persistent critique of public health is that the field has strayed beyond its natural boundaries. Instead of focusing solely on narrow interventions for discrete injuries and diseases, the field has turned its attention to broader health determinants. It is when public health strays into the social/political sphere in matters of war, violence, poverty, and racism that critics become most upset.

The justice perspective does not provide a definitive defense against claims of overreaching. But social justice does provide a counterweight to the prevailing political view of health as primarily a private matter. The justice perspective shows why health is a matter of public concern, with the state having a role not only in the traditional areas of infectious diseases and sanitation, but also in emerging areas such as chronic diseases caused by diet, lifestyle, and the environment. Public health agencies have an obligation to address the root causes of ill health, even while they recognize that socioeconomic determinants have many causes, and solutions, that are beyond public health's exclusive expertise.

- Balancing individual and collective interests. The exercise of the state's coercive power has been highly contentious throughout U.S. history. When public health officials act, they face troubling conflicts between the collective benefits of population health on the one hand, and personal and economic interests on the other. Public health powers encroach on fundamental civil liberties such as privacy, bodily integrity, and freedom of movement and association. Sanitary regulations similarly intrude on economic liberties such as freedom of contract, pursuit of professional status, and use of personal property. Justice demands that government take actions to safeguard the public's health, but that it do so with respect for individuals and sensitivity to the needs of the underprivileged.

In the realm of public health and civil liberties, then, both sides claim the mantle of justice. Finding an appropriate balance is not easy and is fraught with controversy. What is most important to justice is abiding by the rule of law, which requires modern public health statutes that designate clear authority to act and provide fair processes. Policymakers, therefore, should modernize antiquated public health laws to provide adequate power to reduce major risks to the population but ensure that government power is exercised proportionately and fairly. ${ }^{5}$ Fairness requires just distributions of burdens and benefits to all, but also procedural due process for people subjected to compulsory interventions.

Certainly, the justice perspective cannot answer many of the most perplexing 
problems at the intersection of public health and civil liberties such as paternalistic interventions (for example, seat belt laws) or the exercise of powers in health emergencies (for example, avian flu or bioterrorism). These and many other problems pose major dilemmas for the field that neither considerations of justice nor traditional arguments based in beneficence can readily resolve. However, a more serious failure of public policy would be a failure to recognize and give great weight to the demands of social justice when faced with such challenges.

National, state, and local public health functions. The arguments for and against the centralization of political power have remained largely the same over the course of U.S. history and are part of entrenched political ideologies. There is no simple resolution, and initially it might seem that the justice perspective can shed little light on this contentious area. Considerations of social justice do not side with either of the traditional combatants in the federalism debates, as they neither favor federal nor state action. What justice does do is insist that governmental action address the major causes of ill health, particularly among the disadvantaged; that commitment has major implications for political and social coordination.

The justice perspective's emphasis on the multicausal and interactive determinants of health suggests that strategic opportunities for prevention and amelioration of ill health arise at every level of governmental interaction. The challenge of combating the threat of systematic disadvantage can be met only with a systematic response among all levels of government. The level of government best situated for dealing with public health threats depends on the evidence identifying the nature and origin of the specific threat, the resources available to each unit for addressing the problem, and the probability of strategic success.

National obligations. The national government has a duty to create the capacity to undertake essential public health services. A national commitment to capacity building is important because public needs for health and well-being are universal and compelling. The federal government should recognize these needs and invest in a strong public health system. Certain problems demand national attention. A health threat, such as epidemic disease or environmental pollution, might span many states, regions, or the whole country. Further, the solution to problems such as those related to foreign or interstate commerce could be beyond the jurisdiction of individual states. Finally, states simply might lack the expertise or resources to mount an effective response in a major public health emergency.

State/local obligations. Armed with sufficient resources and tools, states and localities have an obligation to fulfill core public health functions such as diagnosing and investigating health threats, informing and educating the public, mobilizing community partnerships, and enforcing state health laws. States and localities are closer to the people and to the problems causing ill health. Delivering public health services requires local knowledge and direct political accountability. States and localities are also often the preferable unit of government when dealing with complex, poorly understood problems. In such cases, the idea of a "laboratory of 
the states" enables local officials to seek innovative solutions.

Harmonized engagement. Because justice emphasizes the multicausal, interactive character of health threats, a system of overlapping and shared responsibility among federal, state, and local governments will most often be required. Governments at all levels have differing degrees of responsibility. This insight was illustrated poignantly during the response to the Gulf Coast hurricanes. It was not that a particular political unit should have had primacy. Rather, each should have played a unique role in a well-coordinated effort.

\section{The Policy Imperatives Of The Justice Perspective}

The public health community has not been successful in gaining attention to or resources for its core mission and essential services. Outside of health emergencies, the public does not demonstrate any particular interest in public health as a priority, and this lack of interest shows in chronic underfunding. From a fiscal perspective, only a tiny fraction of health dollars goes to prevention and population-based services. ${ }^{6}$ Even when attention and resources are ample, it is usually in immediate response to some actual or perceived threat. This leads not to core, stable funding and attention but, rather, to a "disease du jour" mentality. This type of response creates silos, disproportionately funds biomedical solutions, and poses a "no-win" situation for public health agencies, which must respond to the latest fashion but seldom gain the kind of ongoing political attention and economic resources they need to improve the public's health.

The justice perspective offers an opportunity to change this dynamic, and the remainder of this Commentary offers concrete proposals based on the imperatives of population improvement and just distribution of benefits.

- The public health system. Justice, with its concern for human well-being, requires a serious commitment to the public's health. It is for that reason that justice demands a tangible, long-term pledge to the public's health and the needs of the least well-off. Such a commitment, as countless reports have made clear, is lacking. ${ }^{7}$ Funding for prevention and population-based services is inordinately low, and categorical funding for special programs such as bioterrorism and avian flu is limited to a single issue and is time restricted.

To assure that actions can be taken to protect, promote, and provide for the health of the public, there must be a substantial and stable commitment to the public's health at the federal, state, and local levels. Given the gravity and importance of the situation, Congress and the executive branch should create a Trust Fund for Public Health to provide generous and stable resources to rebuild the eroded public health infrastructure and implement core public health functions. Nongovernmental trust-fund approaches, implemented in other countries, should also be explored. The Public Health Leadership Initiative, established by the Trust for America's Health (TFAH), recommends annual, sustained spending of \$1.5-\$2 billion increase to ensure an adequate public health infrastructure. ${ }^{8}$ 
Addressing health determinants. If justice is outcome oriented, then inevitably public health must deal with the underlying causes of poor and good health. The key health determinants include the built environment (for example, transportation and buildings); the natural environment (for example, clean air and water); the informational environment (for example, health information and advertising restrictions); the social environment (for example, social networks and support); and the economic environment (socioeconomic status). ${ }^{9}$ These are all public health problems, but they are not solvable solely by public health agencies. Public health researchers and agencies can provide the intellectual tools for understanding the factual basis of the problems policymakers face. They can act directly and as conveners that mobilize and coordinate government agencies, health care institutions, businesses, the media, academia, and the community.

Obesity policy offers an apt illustration of the numerous ways that public health, together with its partners, can act on the root causes of ill health. By a combination of zoning, public construction, taxation, incentives, regulation, and health information, the state could encourage citizens to eat healthier diets and maintain more active lifestyles. This could be accomplished by changing the inner city, for example, to favor supermarkets over fast foods, recreational facilities and green spaces over roads, mass transportation over automobiles, and so forth. It could involve transformation of schools to ensure healthier snacks and lunches, physical activity, and health education. Critics complain that diet and lifestyle are personal choices outside the appropriate realm of government. However, there is nothing inherently wrong with having the state make healthier choices easier for people to make.

Fair treatment of the disadvantaged. Fair distribution of burdens and benefits, as discussed, is a core attribute of justice. Allocations based on the market or political influence favor the rich, powerful, and socially connected. Even neutral or random allocations can be unjust because they do not benefit those with greatest need. For example, health officials who direct a population to evacuate or shelter in place should foresee that the poor will not have private transportation or the means to stock up on food or supplies. For that reason, justice requires public health officials to devise plans and programs with particular attention to the disadvantaged. Fair distributions should be integral to public health policy and practice, but they take on particular importance when planning for health emergencies or when there is extreme scarcity.

Health emergencies threaten the entire community, but the poor and disabled are at heightened risk. Social justice thus demands more than fair distribution of resources in extreme health emergencies. A failure to act expeditiously and with equal concern for all citizens, including the poor and less powerful, predictably harms the whole community by eroding public trust and undermining social cohesion. It signals to those affected and to everyone else that the basic human needs of some matter less than those of others, and it thereby fails to show the respect 


\section{"The aims of public health deserve a great deal more societal attention and resources than the political community has allowed."}

due to all members of the community. Social justice thus encompasses not only a core commitment to a fair distribution of resources, but it also calls for policies of action that are consistent with the preservation of human dignity and the showing of equal respect for the interests of all members of the community.

- Planning for emergencies involving scarce life-saving resources. Health emergencies pose the potential for mass illness and death, often resulting in extreme scarcity of medical countermeasures, hospital beds, and other essential resources. Rarely will there be sufficient stockpiles or surge capacity to meet mass needs. For example, the U.S. influenza preparedness plan anticipates marked shortages of vaccines, antiviral medications, and medical equipment.

What does justice tell us about how to ration scarce, life-saving resources? In the context of influenza, the United States focuses on key personnel and sectors such as government, biomedical researchers, the pharmaceutical industry, health care professionals, and essential workers or first responders. These apparently neutral categories mask injustice. In each case, people gain access to life-saving technologies based on their often high-status employment. This kind of health planning leaves out, by design, those who are unemployed or in "nonessential" jobs-a proxy for the displaced and devalued members of society. Consequently, public health planning based on pure utility, although understandable, fails to have sufficient regard for the disenfranchised in society. ${ }^{10}$

- Fair distribution from a global perspective. Perhaps the most extreme injustices arise in the global allocation of health resources. Developing countries suffer the multiple, compounding burdens of destitution (lack of medical equipment, health professionals, and hospitals), impoverished environments (drought, famine, and contaminated drinking water), and extremely poor health (tuberculosis, malaria, and HIV). They also lack a scientific infrastructure. Realistically, scarce resources will go to those countries where products are owned and manufactured. This reality can have devastating consequences for poor countries that cannot compete economically for expensive health resources. Social justice views all lives as having equal value, so there is a moral justification for fair allocation from a global perspective. Even from a less altruistic perspective there are reasons to invest in poor regions. Improved surveillance and response can help in early detection and containment of infectious disease outbreaks, affording universal benefits.

\section{A Policy Landscape Informed By Social Justice}

What would the policy landscape look like if it were informed by a robust conception of social justice? The political community would embrace, rather than condemn, a wide scope for the public health enterprise; value the public good as 
much as personal and economic liberty; view the public good as involving a commitment to the health and equal worth of all members of the community; and view federalism as a shared responsibility for health improvement rather than an ideological battleground between national power and states rights.

Social justice would spur important policy shifts. Political leaders would create a trust fund allocating funds on a sustained basis sufficient to assure an adequate public health infrastructure; use a variety of tools (such as zoning, taxation, incentives, regulations, and information) to address the determinants of ill health, including reduction of socioeconomic disparities; devise programs and plans to assure the health and safety of the most vulnerable, particularly in public health emergencies; and devote substantial resources to meeting global needs for essential public health services. These measures, and many more, would not ensure equality in health but would soften some of the most egregious inequities.

The central claim of this Commentary is that a commitment to social justice lies at the heart of public health. This commitment is to the advancement of human well-being. It aims to lift up the systematically disadvantaged and in so doing further advance the common good by showing equal respect to all individuals and groups who make up the community. Justice in public health is purposeful, positivistic, and humanistic. The aims of public health deserve a great deal more societal attention and resources than the political community has allowed. The authors thank Benjamin Berkman, Sloan Fellow at the Georgetown University Law Center, for research and editorial assistance.

\section{NOTES}

1. D.E. Beauchamp, "Public Health as Social Justice," in New Ethics for the Public's Health, ed. D.E. Beauchamp and B. Steinbock (New York: Oxford University Press, 1999), 105-114.

2. J. Rawls, A Theory of Justice (Cambridge: Harvard University Press, 1971).

3. M. Powers and R. Faden, Social Justice: The Moral Foundations of Public Health and Health Policy (New York: Oxford University Press, 2006).

4. Ibid.

5. L.O. Gostin, "Public Health Law in an Age of Terrorism: Rethinking Individual Rights and Common Goods," Health Affairs 21, no. 6 (2002): 79-93.

6. K.W. Eilbert et al., Measuring Expenditures for Essential Public Health Services (Washington: Public Health Foundation, 1996).

7. See, for example, Institute of Medicine, The Future of the Public's Health in the Twenty-first Century (Washington: National Academies Press, 2003).

8. Public Health Leadership Initiative, A Blueprint for Healthy People in Healthy Communities in the Twenty-first Century (Washington: Trust for America's Health, forthcoming).

9. L.O. Gostin, J.I. Boufford, and R.M. Martinez, "The Future of the Public's Health: Vision, Values, and Strategies," Health Affairs 23, no. 4 (2004): 96-107.

10. L.O. Gostin, "Medical Countermeasures for Pandemic Influenza: Ethics and the Law," Journal of the American Medical Association 295, no. 5 (2006): 554-556. 